\title{
Gastrointestinal Metastatic Melanoma: The Key for Diagnosis
}

\author{
Daniela Filipa Soares Santos Marta Costa Patrícia Carvalho Rui M. Santos \\ Armando Carvalho
}

Internal Medicine, Centro Hospitalar e Universitário de Coimbra and University Clinic of Internal Medicine, Faculty of Medicine, University of Coimbra, Coimbra, Portugal

\section{Keywords}

Melanoma · Gastric metastasis · Duodenal metastasis

\section{Melanoma metastático gastrointestinal: a chave para o diagnóstico}

\section{Palavras Chave}

Melanoma $\cdot$ Metástase gástrica $\cdot$ Metástase duodenal

An 80-year-old Caucasian woman was hospitalized with a 2 -month course of intermittent fever $\left(\max .38^{\circ} \mathrm{C}\right)$, asthenia, weight loss (12\%), anorexia and nausea. Her medical history includes breast cancer submitted to radical mastectomy and axillary lymph node dissection, papillary thyroid carcinoma and pulmonary and ocular tuberculosis that had been treated more than 5 years previously. She had heart failure, arterial hypertension, dyslipidaemia and obesity under treatment.

Physical examination showed obesity and left upper limb lymphedema. Abdominal and rectal examinations were unremarkable. A laboratory study revealed iron deficiency anaemia with haemoglobin $10 \mathrm{~g} / \mathrm{dL}$ and ferritin $10 \mathrm{ng} / \mathrm{mL}$ (normal $=10-120 \mathrm{ng} / \mathrm{mL}$ ), elevated lactate dehydrogenase 1,379 U/L (normal $<247 \mathrm{U} / \mathrm{L}$ ), aspartate transaminase $59 \mathrm{U} / \mathrm{L}$ (normal $<31 \mathrm{U} / \mathrm{L}$ ), alkaline phosphatase $185 \mathrm{U} / \mathrm{L}$ (normal $=30-120 \mathrm{U} / \mathrm{L}$ ), C-reactive protein $21.9 \mathrm{mg} / \mathrm{dL}$ (normal $=0-0.5 \mathrm{mg} / \mathrm{dL}$ ) and a normal procalcitonin value. A bacterial, mycobacterial, viral or fungal infectious disease was excluded by blood, urine and sputum cultures. A thoracic abdominal and pelvic computerized tomography (CT) scan was negative for malignant disease.

During hospital stay she presented with intense nausea and vomiting during most meals. A red blood cell transfusion was necessary due to progressive decrease in haemoglobin. Upper endoscopy was performed showing multiple black nodular lesions in the stomach and duodenum (Fig. 1). Narrow-band imaging revealed the presence of black patches on the top of these nodular lesions (Fig. 2). Histopathological examination showed an epithelioid malignant injury with intense and diffuse HMB45 expression suggestive of pigmented melanoma (Fig. 3). The diagnosis of gastrointestinal karger@karger.com www.karger.com/pjg

Karger $\stackrel{\text { ' }}{5}$

BOPEN ACCESS (c) 2021 Sociedade Portuguesa de Gastrenterologia. Published by S. Karger AG, Basel

This is an Open Access article licensed under the Creative Commons Attribution-NonCommercial-4.0 International License (CC BY-NC) (http://www.karger.com/Services/OpenAccessLicense), applicable to the online version of the article only. Usage and distribution for commercial purposes requires written permission.
Correspondence to:

Daniela Filipa Soares Santos, danielafssantos@gmail.com 
Fig. 1. a In gastric mucosa, multiple black nodular lesions were identified with white light. The two largest lesions of $5 \mathrm{~mm}$ were present on the distal body. These lesions were suggestive of melanoma metastasis. b Similar black nodular lesion of $3 \mathrm{~mm}$ on the duodenum.
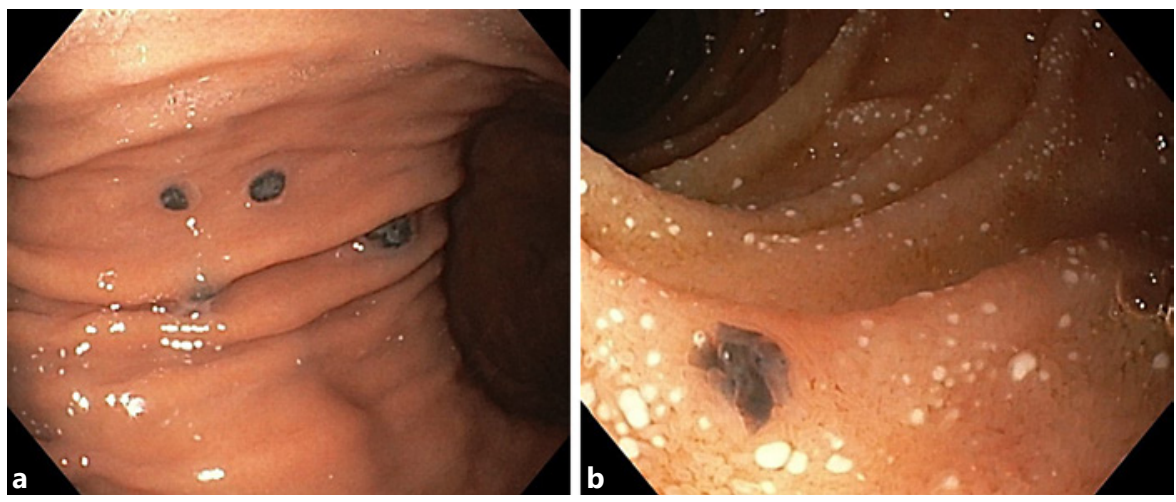

Fig. 2. Narrow-band imaging: black patches present on the summit of elevated lesions. The lesions' base showed an enlarged regularly placed oval and elongated pit pattern in contrast to a small pit pattern of the surrounding normal gastric mucosa.

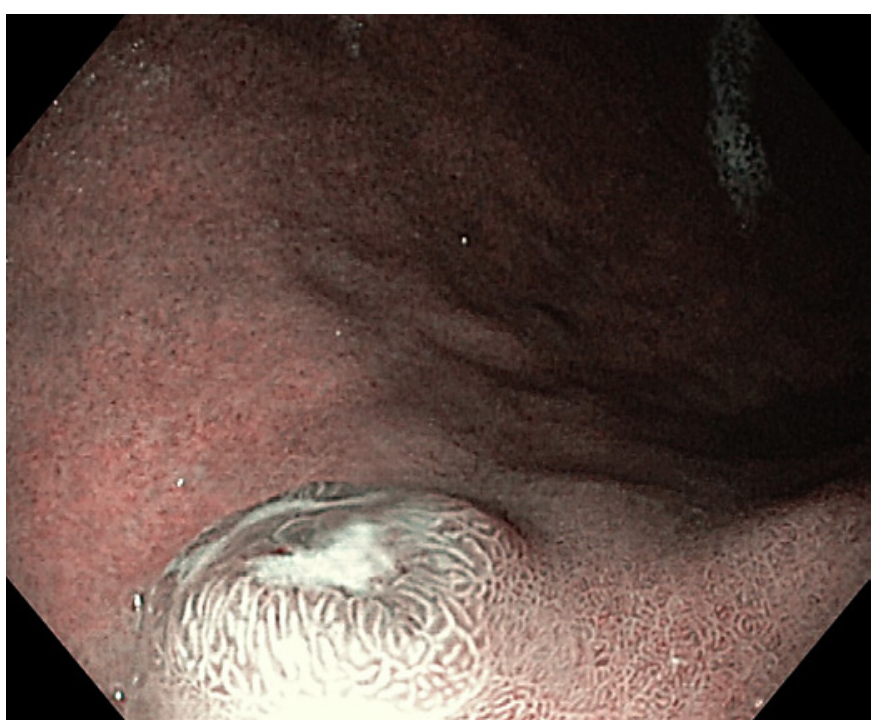

metastatic melanoma was made. A positron emission tomography/CT scan revealed the presence of bone, cervical and mediastinal lymph node metastases. BRAF gene mutation was not present. The primary tumour was not found. Due to the patient's limited functional status no treatment was initiated, and death occurred 4 months after diagnosis.

We present a metastatic gastric melanoma in an elderly woman without any history of melanoma with a very rare presentation. Melanoma gastrointestinal metastases are rare and represent a late stage of malignant disease. Its incidence in clinical and autopsy series varies between 0.2 and $0.7 \%$, and it has been reported that only $7 \%$ of gastric metastases are due to malignant melanoma [1]. Primary tumours commonly occur in the skin but can also develop from other tissues containing melanocytes such as the meninges, gastrointestinal tract and eyes. Pri- mary or metastatic malignant melanoma of the gastrointestinal tract is an uncommon entity, and more than $90 \%$ of cases are identified only during autopsy. The most common gastrointestinal metastatic sites are the jejunum and ileum, followed by the colon, rectum and stomach [2]. The diagnosis is difficult due to non-specific symptoms. Symptoms are present in only $1-4 \%$ of patients, and they are related to complications such as haemorrhage, obstruction and perforation [3]. Imaging studies have low sensitivity for diagnosing, and CT sensitivity is only $60-70 \%$ in detecting metastases [4]. Gastrointestinal endoscopy allows the diagnosis [3]. Depending on the patient's functional status, treatment includes surgical resection, immunotherapy, targeted and radiation therapy. The average life expectancy following diagnosis is $4-6$ months [5]. 

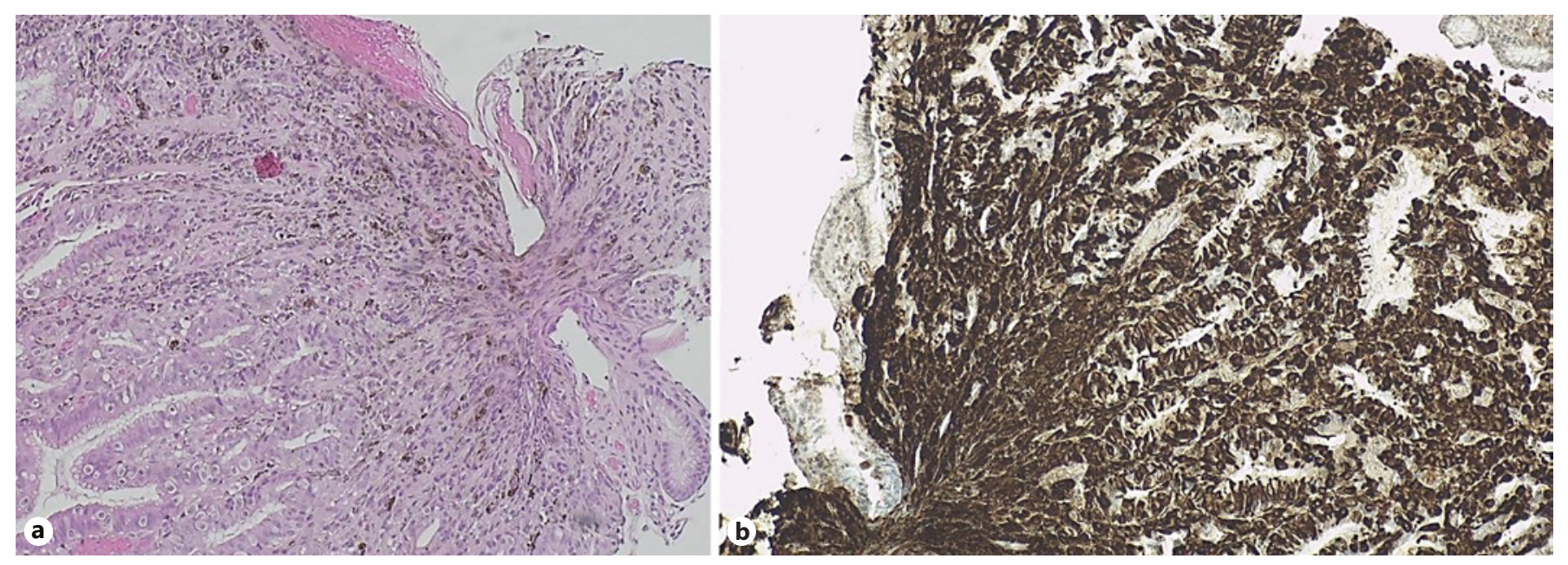

Fig. 3. a Lamina propria diffuse infiltration by epithelioid malignant neoplasia. Haematoxylin-eosin staining. $\times 40$. b Tumoural cells show intense and diffuse expression for HMB45. HMB45. $\times 40$.

\section{Statement of Ethics}

This study did not require review or approval by the appropriate ethics committee. Written informed consent was obtained from the patient's next of kin.

\section{Conflict of Interest Statement}

The authors have no conflicts of interest to declare.

\section{Funding Sources}

None declared.

\section{Author Contributions}

Daniela Soares Santos drafted the manuscript. Marta Costa helped writing the manuscript. Patrícia Carvalho, Rui M. Santos and Armando Carvalho revised the manuscript critically. All authors commented on drafts of the paper. All authors approved the final draft of the article.

\section{References}

Gastric and Duodenal Melanoma Metastases
1 Kobayashi O, Murakami H, Yoshida T, Cho $\mathrm{H}$, Yoshikawa T, Tsuburaya A, et al. Clinical diagnosis of metastatic gastric tumors: clinicopathologic findings and prognosis of nine patients in a single cancer center. World J Surg. 2004 Jun;28(6):548-51.

2 Dasgupta T, Brasfield R. Metastatic melanoma. A clinicopathological study. Cancer. 1964 Oct;17(10):1323-39.

3 Ercolino GR, Guglielmi G, Pazienza L, Urbano F, Palladino D, Simeone A. Gallbladder and small bowel metastasis of regressive melanoma: a case report. BJR Case Rep. 2018 Aug;5(1):20180032.

4 Wong K, Serafi SW, Bhatia AS, Ibarra I, Allen EA. Melanoma with gastric metastases. J Community Hosp Intern Med Perspect. 2016 Sep;6(4):31972.

5 Farshad S, Keeney S, Halalau A, Ghaith G. A case of gastric metastatic melanoma 15 years after the initial diagnosis of cutaneous melanoma. Case Rep Gastrointest Med. 2018 Jul;2018:7684964. 